\title{
ENTRE O PODER LOCAL E A ELITE CENTRAL: UM ENSAIO SOBRE A
}

PARTICIPAÇÃO POLÍTICA NO BRASIL'

1- Versão inicial deste trabalho foi apresentada no Congresso Internacional Rosário 2010 - Profundizando la Democracia como Forma de Vida, organizado pela Facultad de Ciencia Política y Relaciones Internacionales, Universidad Nacional de Rosario. 13-16 de Mayo, 2010 - Rosario, Argentina.

\section{Osmir Dombrowski}

Licenciado en Historia y Doctor en Ciencias Políticas por la Universidade de São Paulo (2003), actualmente es profesor adjunto del Programa de Posgrado en Ciencias Sociales de la Universidade Estadual do Oeste do Paraná donde participa en el grupo de investigación "Democracia y Desarrollo" y lleva a cabo estudios con énfasis en la democracia, la ciudadanía y análisis del poder local. Es co-autor del Mapa do Trabalho Informal no Município de São Paulo. 


\title{
Resumo
}

O ensaio busca compreender o absentismo verificado em instituições participativas locais no Brasil, sem recorrer a julgamentos morais que condenam o comportamento da população. A hipótese que orienta o trabalho coloca em questão o grau de efetividade dessas instituições, bem como a autonomia dos municípios no arranjo federativo nacional e sugere que as instâncias participativas ocupam uma estreita margem deixada pelo governo central a ser disputada junto ao poder local, sugerindo que a dinâmica da luta pela sua ocupação possui grande poder explicativo sobre o absentismo dos setores populares.

\section{Palavras-Chaves}

Participação, Absentismo, Poder Local, Município.

\begin{abstract}
This essay seeks to understand the absenteeism verified in local participatory institutions in Brazil, without resorting to moral judgments that condemn the behavior of the population. The hypothesis that guides this work calls into question the degree of effectiveness of these institutions, as well as the autonomy of the municipalities in the national federative arrangement and suggests that the participatory instances occupy a narrow margin left by the central government to be held next to local power, suggesting that the dynamics of the struggle for their occupation has great explanatory power on the absenteeism of the popular sectors.
\end{abstract}

\section{Keywords}

Participation, Absenteeism, Local Power, Municipality. 
A participação direta dos cidadãos na vida política do Brasil ganhou institucionalidade na Constituição de 1988 que consagra o "plebiscito", o "referendo" e a "iniciativa popular" como "instrumentos de exercício da soberania popular" ao lado do "sufrágio universal" e do "voto direto e secreto" e reconhece a participação cidadã como princípio básico nos processos de elaboração e gestão de políticas públicas, notadamente nos capítulos dos chamados direitos sociais. Passados mais de vinte anos da promulgação daquela carta, se acumulam experiências e informações suficientes para que alguns aspectos e dinâmicas processuais, que se organizaram a partir daquele princípio, possam ser submetidos a análises e avaliações. Este ensaio pretende contribuir com esse esforço avaliativo tecendo algumas considerações sobre um problema que se apresenta com relativa frequência no interior de tais processos: o absentismo da população.

O comportamento absentista, é óbvio, não deve ser tomado como resposta padrão da população a todas às instituições participativas em atividade no país. Tal seria uma generalização imprópria. É sabido que o funcionamento dessas instituições apresenta desempenho desigual com variações no tempo e no espaço: em alguns casos funcionam muito bem, em outros não funcionam e entre estes dois extremos, é possível constatar uma extensa gama de situações híbridas. Há alguns anos o autor vem coordenando e orientando pesquisas sobre instituições participativas na região Oeste do estado do Paraná com ênfase nos Conselhos Gestores Municipais e ao longo desse tempo pôde estabelecer uma interlocução privilegiada com muitos personagens desse campo. Nesse percurso não foram poucos os momentos em que teve a oportunidade de testemunhar a ocorrência de reuniões como Conferências Municipais e Audiências Públicas completamente esvaziadas, bem como de constatar a existência de Conselhos Gestores Municipais inoperantes ou reduzidos à sua dimensão burocrático-legal e ouvir gestores, técnicos e dirigentes de associações civis, bem ou mal intencionados, atribuindo ao povo a responsabilidade pelos problemas no funcionamento de instituições participativas. "Falta de interesse", "acomodação", "preguiça", "desinformação" ou, simplesmente, "ignorância", são algumas das principais razões propaladas, amiúde, para explicar o baixo nível de participação popular. Por considerar que tais condições - quando verdadeiras - não deveriam ser tomadas como justificativas para o imobilismo, e sim que deveriam ser compreendidas como um dado da realidade a ser transformada pela prática política participativa, o autor foi colocado diante da necessidade de entender as razões daqueles que não participam para afastar preconceitos arraigados e contribuir com a construção de caminhos que levem ao aprofundamento da democracia entre nós.

O ensaio é aberto com uma breve explanação sobre algumas razões que competem para a disseminação de um comportamento absentista em geral, e conclúído com o esboço de uma hipótese explicativa aplicável à realidade brasileira. 
$\overline{2-\text { Esta seção retoma com }}$ algumas poucas alterações o trabalho apresentado no $4^{\circ}$ Seminário Nacional Estado e Políticas Sociais no Brasil (Dombrowski e Parmigiani, 2009).

3- Veja por exemplo os estudos clássicos de Downs (1999) e Olson (1999).

4- Ver dados para diferentes regiões metropolitanas do pais em Santos, Queiroz e Azevedo, (2004).

\section{TRÊS RAZÕES PARA NÃO PARTICIPAR²}

\section{a) O problema do custo}

Primeiro, é preciso dizer que o custo da participação é um problema há muito conhecido pela teoria democrática ${ }^{3}$, porém com frequência minimizado, quando não completamente esquecido, nas análises dos processos participativos. E não nos parece desnecessário observar que esse custo é maior quanto mais pobre for o cidadão sobre o qual ele incidir. Esta é, sem dúvida, uma das razões que levam Conselhos Gestores Municipais de diferentes regiões do Brasil a apresentarem uma configuração sócio-demográfica semelhante: os conselheiros municipais são, em sua maioria, brancos, com nível escolar médio e superior e renda concentrada em uma faixa entre 08 e 15 salários mínimos ${ }^{4}$. É evidente a distorção nesse perfil em detrimento dos setores mais fragilizados da população. Ou seja, é marcante que a participação tem sido maior entre os segmentos médios e superiores e menor entre as classes subalternas, as quais seriam, teoricamente, as mais interessadas em influenciar nos processos de alocação dos recursos públicos.

Ativistas de classe média podem, por exemplo, desconsiderar o custo do transporte de um cidadão até o local de uma reunião. Desempregados, diaristas e trabalhadores informais de modo geral, que estão sempre preocupados com a próxima refeição, com o aluguel, a mercearia e as contas a pagar no final do mês, não podem desprezar o valor correspondente a uma ou duas passagens. E existem ainda outros custos diretos e reais além dos gastos com transporte. Se uma reunião implicar em uma refeição fora de casa, esse custo pode dificultar a participação de alguns e inviabilizar a de outros. Se uma reunião for chamada para horário comercial, em dias úteis; o trabalhador empregado com jornada fixa estará automaticamente alijado, pois os patrões não cultivam o hábito de dispensar seus funcionários durante o expediente para participarem de atividades políticas. $\mathrm{O}$ trabalhador por "conta própria", apesar de dispor da liberdade hipotética de "fazer o próprio horário", deve contabilizar aquilo que deixa de ganhar como custo de sua participação. Assim, o retorno tem que ser compensador, caso contrário, também ele se absterá de participar. Nesse quesito, o funcionário público no Brasil leva uma pequena vantagem: muitos conseguem liberação, ainda que seja em sistema de compensação de horas, o que indica que a qualidade dos empregos públicos em nosso país, sob muitos aspectos, é melhor que a oferecida pelo setor privado. O irônico é que muitos funcionários públicos, quando investidos no papel de representantes governamentais, encaram sua participação nos Conselhos Gestores como parte de suas atribuições funcionais e convocam reuniões para o horário de expediente. Registro aqui, de passagem, que todas as Conferências Municipais das quais participei ao longo dos últimos anos como conferencista convidado, sem nenhuma exceção, foram realizadas em dias de semana e em horário comercial. 
A redução de custos para o trabalhador pode encontrar solução no agendamento de reuniões descentralizadas, nos bairros, à noite ou nos finais de semana. A convocação de reuniões para horários alternativos, praticada sempre que se espera um mínimo que seja de participação popular, expõe, entretanto, outra dimensão do problema do custo da participação: como mensurar o custo de algumas horas do descanso do trabalhador, ou de alguns momentos do convívio com a família ou com os amigos? Será que um cidadão pode ser considerado culpado por preferir a família ou os amigos a uma reunião cujos resultados lhes parecem incertos? O antropólogo Carlos Rodrigues Brandão (1990) chama a nossa atenção para uma diferença entre o que ele classifica como "espaços sociais de convívio", aqueles em que a associação de pessoas é motivada pela vontade de estar junto e pela situação prazerosa que esta convivência proporciona e os "espaços sociais de participação", criados com a intenção de produzir bens ou serviços através de um trabalho coletivo em que a pessoa se associa voluntariamente ou não. A participação das pessoas nos "espaços de convívio" costuma ser uma escolha orientada pelo prazer, pela vontade de estar junto, enquanto nos "espaços de participação", o sujeito, quando escolhe, sabe que vai realizar um trabalho, uma tarefa, ou uma obrigação que até pode ser transformada em convivência quando, por exemplo, ao final de uma atividade se realiza uma festa com comida e bebida para todos os participantes como é comum ocorrer nos "mutirões". Quando se convoca um popular para reuniões do tipo das Conferências Municipais ou Audiências Públicas, podemos dizer que se apela para ele que venha cumprir uma "obrigação" de cidadania em um "espaço de participação", de trabalho, sem os prazeres associados aos momentos de convivência. É bastante natural, portanto, que as pessoas prefiram o convívio com amigos e familiares à obrigação da participação em frias reuniões políticas. A experiência da participação até pode se tornar uma relação de convivência prazerosa, mesmo quando se apresenta como uma obrigação, mas essa possibilidade é maior quando vivida autonomamente entre sujeitos sociais iguais e no ambiente dos Conselhos, das Audiências Públicas e das Conferências persistem marcas de distinção que reforçam a desigualdade entre seus membros tais como o conhecimento de regras formais e informais de comportamento e manifestação que dão forma às reuniões e o domínio da linguagem técnica específica de cada área em pauta, sobre o qual falaremos a seguir.

b) O problema da linguagem técnica

A fala sustentada pelo conhecimento técnico no interior de instituições participativas, quase sempre, é manipulada para suprimir ou desqualificar a participação popular. Através dela os membros das classes subalternas são colocados em situação de inferioridade, pois o conhecimento técnico hierarquiza as relações no interior dessas instituições, separando aqueles que dominam o saber daqueles que devem permanecer calados por não deter o conhecimento. $\mathrm{O}$ absentismo pode e deve ser pensado como uma reação a este processo de submissão, onde a ausência é apenas um mecanismo usado para evitar a humilhação provocada pela exposição de uma suposta ignorância. 
Por não perceber o conhecimento técnico como instrumento para submissão da participação, muitos propõem a realização de "cursos de capacitação" para melhor qualificar a participação popular. Entramos aqui em um terreno bastante controverso, portanto, é importante deixar o mais claro possível o nosso pensamento a esse respeito. E o nosso raciocínio é bem simples: se o povo precisa ser "preparado" para participar de uma instância política é porque ela - a instituição - não está preparada para receber o povo, ou então, as tais "capacitações" propostas têm como objetivo disciplinar a ação política popular, contrapondo um conhecimento técnico pré-definido às formas populares de organização e reivindicação. Assim, não se trata de oferecer cursos com o objetivo de preparar o povo, ou de moldar seu comportamento ao padrão que as elites técnicas e políticas estabelecem como correto. Antes, se deveriam formatar essas instituições para permitir a manifestação popular, submetendo, em última instância a técnica aos seus interesses. $O$ que não quer dizer, insisto, que as classes subalternas não tenham direito de acessar livremente todo o conhecimento técnico e científico acumulado pela humanidade. Quer dizer, isto sim, que a participação dos setores populares não pode ser submetida pela manipulação de conhecimentos estranhos ao seu universo, elevados à condição de fonte de autoridade no interior de instâncias políticas.

c) O problema da efetividade

Se os custos da participação recaem com maior intensidade sobre os segmentos mais pobres da população, precisamos considerar também que os grupos dominantes, por sua própria condição, reúnem melhores condições para defender seus interesses. Mesmo não participando diretamente dos processos decisórios os setores poderosos da sociedade conseguem mobilizar outros recursos e instrumentos para bloquear ações contrárias aos seus interesses, antes, durante e após os procedimentos deliberativos. Eles sempre podem contar, por exemplo, com políticos apaniguados no interior do Estado ou movimentar a pesada máquina da justiça em sua defesa. E pouca coisa tem capacidade de esvaziar uma instância participativa como a simples suspeita de que suas decisões podem não ser implementadas. Este ponto é breve por ser demasiado evidente: quantos se dispõem a suportar os custos da participação e enfrentar violentos processos de submissão desencadeados no interior dos espaços políticos sabendo que seus esforços poderão ser em vão?

Que sua simplicidade, entretanto, não oculte sua amplitude. O problema da efetividade coloca em dúvida o alcance do caráter deliberativo das reuniões para as quais o povo é chamado. Particularmente no caso brasileiro, qual é o verdadeiro grau de efetividade das Audiências Públicas, das Conferências Municipais e dos Conselhos Gestores, mesmo aqueles que são apresentados como "deliberativos" pela legislação? A hipótese que apresentamos a seguir não apenas coloca em questão a efetividade das instituições participativas no Brasil, como interroga sobre o nível de autonomia dos governos locais no 
interior do arranjo federativo nacional e sugere que os instrumentos de participação em funcionamento ocupam uma estreita margem de deliberação deixada pelo governo central a ser disputada junto aos poderes locais, concluindo que a dimensão dessa faixa e a dinâmica da luta pela sua ocupação possuem grande poder explicativo sobre o absentismo dos setores populares.

\section{ENSAIO PARA A CONSTRUÇÃO DE UMA HIPÓTESE EXPLICATIVA}

Há dois argumentos fundamentais a serem considerados na formulação da hipótese acima anunciada. Primeiro, deve-se anotar o peso da tradição no pensamento político brasileiro e a forma como o "poder local" é enquadrado por esta tradição intelectual. Trata-se de uma referência comum o fato de que o "local" na política brasileira tem sido tomado como lócus de desmandos autoritários por parte das elites locais ou regionais que submetem o aparelho do Estado aos seus desígnios particulares, afastando todos os demais segmentos sociais e exercendo o poder de forma perdulária e quase sempre corrupta. A origem e a disseminação dessa forma de pensamento no Brasil nos remetem às primeiras décadas da República.

Praticamente toda reflexão política e social do Brasil das décadas de 1920 e 1930 , fazia - como não podia deixar de ser - uma crítica profunda e vigorosa da descentralização republicana que abandonara o país ao apetite das oligarquias regionais de base rural (PÉCAUT, 1990). A ideologia centralizadora em gestação naqueles anos se constitui em uma espécie de negação do liberalismo oligárquico ${ }^{5}$ e da correspondente farsa democrática que caracterizou a Primeira República brasileira ${ }^{6}$. Mas em vez de apontar para o aprofundamento da democracia, influenciados por um cenário internacional marcado pela ascensão de regimes autoritários, os ideólogos da centralização no Brasil puderam facilmente relacionar democracia com dominação oligárquica e negando uma, recusaram também a outra. Os germens do centralismo no Brasil trazem, portanto, marcas de um pensamento profundamente antidemocrático.

É de Oliveira Vianna, célebre precursor da sociologia política brasileira, uma das mais bem acabadas justificativas do centralismo antidemocrático. Para aquele que foi um dos colaboradores do novo regime que ascenderia ao poder com o presidente Getúlio Vargas na Revolução de 1930:

"Os grandes construtores políticos da nossa nacionalidade, os verdadeiros fundadores do poder civil, procuram sempre, como o objetivo supremo da sua política, consolidar e organizar a nação por meio do fortalecimento sistemático da autoridade
5- $A$ expressão "liberalismo oligárquico” não é - como pode parecer à primeira vista - contraditória: ela apenas pretende revelar que as oligarquias rurais no Brasil se aproveitaram do lhe convinha no ideário liberal para legitimar o exercício poder político na forma de uma república oligárquica que excluía cerca de $85 \%$ da população da vida politica.

6- Eleições com voto aberto, o cadastramento de eleitores a cargo dos próprios interessados, o "voto de defuntos", $o$ "voto bico-de-pena" que existia apenas na redação das atas, ao lado de outras artimanhas que culminavam com o pronunciamento dos vencedores por uma sessão do Congresso Federal a quem competiao "reconhecimento" do processo, compunham o sistema eleitoral vigente que garantia a permanência da elite no poder. 
7- Sobre a saga da ideologia desenvolvimentista no Brasil ver Bielschowsky (1995). nacional. Os apóstolos do liberalismo nos dão, ao contrário, o municipalismo, o federalismo, a democracia como a última palavra do progresso político". (VIANNA, 2005, p. 290.)

Neste país sem povo e sem elite, porque contido no interior dos latifúndios, dizia Vianna, o povo não desenvolveu "consciência perfeita e clara da sua unidade nacional" e "o sentimento profético de um alto destino histórico", tarefa que agora só poderia ser realizada pela "ação lenta e contínua do Estado - um Estado soberano, incontrastável, centralizado, unitário, capaz de impor-se a todo o país pelo prestígio fascinante de uma grande missão nacional". (VIANNA, 2005, p. 366.)

O que se passa nos anos seguintes à Revolução de 1930 é a consolidação do "desenvolvimentismo" como ideologia hegemônica: de uma vaga idéia de "progresso" - presente na bandeira nacional republicana, mas nunca suficientemente definida - se caminha para um pensamento muito bem articulado que fazia do Estado o condutor do processo de modernização nacional ${ }^{7}$. Nesse processo de conquista da hegemonia pelo pensamento desenvolvimentista o país iria aparecer dividido em dois: um, urbano e industrial, ligado ao futuro e ao mundo moderno. O outro, rural e agrícola, ligado ao passado, ao mundo feudal, ao latifúndio. O poder do Estado central, condutor do processo de modernização, sediado na capital, aparece ligado ao primeiro mundo, e os poderes locais, sediados no interior, aparecerão, definitivamente, ligados ao atraso do mundo rural e oligárquico: este, no pensamento político brasileiro, passou a ser repositório dos resíduos feudais da colonização portuguesa, o mundo dos desmandos oligárquicos, do coronelismo, do clientelismo e do patrimonialismo.

Alguns entre nós chegaram a imaginar que essa forma de pensamento havia sido sepultada pela Constituição de 1988. Afinal, aquela Carta, fortemente influenciada pelo desmoronamento de um governo federal carente de legitimidade em contraste com governos locais eleitos pelo voto popular, deu vazão às aspirações descentralizadoras e colocou o município ao lado dos Estados e da União como ente federal autônomo e autogovernado, com executivo e legislativo próprios e independentes. A nova Constituição limitou, inclusive, o poder de intervenção das unidades superiores sobre as locais, condicionando ações desse tipo à aprovação do legislativo. Tudo isso coroado com uma nova partilha da receita fiscal entre os diferentes níveis de governo que aumentou a receita dos municípios para um patamar inédito na história: especialistas calculam que nos primeiros anos da década de 1990 a parcela dos municípios passou a ser de cerca de $16 \%$ do total das receitas, contra um valor próximo a 8\% recebido no início da década anterior. (Cf. ALMEIDA \& CARNEIRO, 2003; SILVA 2002; VARSANO 1998.) 
Muito breve, entretanto, começariam operar mecanismos de restrição à autonomia fiscal dos governos municipais. A partir de meados da década de 1990, ao passo que o governo federal promovia a criação de novos tributos, especialmente, "contribuições sociais" não sujeitas à divisão com outras esferas de governo, os municípios que sentiam ainda o peso de dívidas passadas, se viram pressionados pelo aumento das despesas com novas responsabilidades sociais e pelas vinculações orçamentárias obrigatórias nas áreas da saúde e da educação básica. Como resultado dessa tendência, nos dias atuais pelo interior do Brasil, quando se aproxima o fim do ano civil, assistimos estupefatos a prefeituras municipais reduzindo seu horário de expediente (literalmente fechando as portas!) como forma de conter despesas - basicamente energia elétrica e telefone - na tentativa de equilibrar seu caixa e manter-se dentro dos preceitos estabelecidos pela Lei de Responsabilidade Fiscal.

Com isso introduzimos também o segundo argumento que sustenta nossa hipótese. Verificamos que o movimento no sentido de limitar a autonomia das unidades subnacionais com a imposição de novas responsabilidades à administração municipal ao lado das vinculações orçamentárias, foi acompanhado por uma decidida política de incorporação de instrumentos de participação local no desenho institucional da gestão das políticas públicas, notadamente, na chamada área social. Dados divulgados pelo IBGE - Instituto Brasileiro de Geografia e Estatística, indicam que já na virada do milênio existiam mais de 26 mil conselhos gestores municipais em todo o país, perfazendo uma média de quase cinco por município e em apenas vinte localidades não foram encontrados qualquer tipo de conselho. (DOMBROWSKI, 2008.)

A disseminação dos conselhos municipais no Brasil é um fato que pode ser explicado por diferentes fatores, incluindo a pressão de movimentos sociais e setores progressistas da elite política, mas, insisto, não pode ser feito sem que se considere a relação entre os governos central e locais e a posição subordinada destes no interior da estrutura fiscal. $\mathrm{Na}$ área da Saúde, o processo de descentralização enunciado na Constituição de 1988 ganha consistência e se concretiza a partir da década de 1990. Os conselhos e as conferências municipais, previstos na estrutura do Sistema Único de Saúde - SUS, se tornariam, naqueles anos, condição para a habilitação dos municípios para receberem repasses dos recursos necessários para o gerenciamento dos serviços de saúde em seus territórios (Lei $8.142 / 1990)$.

$\mathrm{Na}$ área da Assistência Social verifica-se que a descentralização e a participação previstas na Constituição ganham regulamentação nos anos 1990 com a Lei Orgânica da Assistência Social - LOÁS (Lei 8.742/1993) a qual institui os conselhos nacional, distrital, estaduais e municipais como "as instâncias deliberativas do sistema descentralizado e participativo de assistência social, de caráter permanente e composição paritária entre governo e sociedade 
$\overline{\text { 8- http://www.direitosda- }}$ crianca.org.br (último acesso em 20/02/2010). civil" (Art. 16). A LOAS é explícita, ainda, ao considerar "a instituição e o funcionamento" de Conselhos Municipais como condição para o repasse de verbas da União (Fundo Nacional de Assistência Social) aos municípios (Art. 30).

Também a Lei 8069/1990, conhecida como ECA, Estatuto da Criança e do Adolescente, preconiza que a União "fica autorizada a repassar aos estados e municípios, e os estados aos municípios, os recursos referentes aos programas e atividades previstos nesta Lei, tão logo estejam criados os conselhos dos direitos da criança e do adolescente nos seus respectivos níveis". E hoje, os conselhos estaduais estão presentes nas 27 unidades federativas do País, e cerca de $92 \%$ dos municípios brasileiros contam com essas estruturas conforme informa o sitio oficial do Conselho Nacional da Criança e do Adolescente ${ }^{8}$.

Na Educação, a lei que criou o Fundo de Manutenção e Desenvolvimento do Ensino Fundamental e Valorização do Magistério - FUNDEF, Lei 9.424/1996, determinou a criação de conselhos com a atribuição de supervisionar a aplicação dos recursos provenientes desse fundo e a realização do Censo Escolar anual no âmbito dos municípios. Também o Programa Nacional de Alimentação Escolar, desde o ano de 2001, determina que os municípios instituam Conselhos de Alimentação Escolar com a participação de representantes dos poderes Executivo e Legislativo, de professores, pais de alunos e "outro segmento da sociedade civil" para credenciar o município para recebimento das verbas desse fundo.

Esta parece ser, portanto, a tendência dominante explicitada em diferentes leis nas mais estratégicas áreas de atuação do Estado brasileiro: a criação de conselhos e a realização de conferências em âmbito municipal foi obtida graças a pressões do governo central, que se utilizou para isso da sua condição de principal recolhedor dos tributos e distribuidor dos recursos arrecadados. Deve-se observar ainda que, do ponto de vista institucional, os municípios, definidos pela Constituição como entes federados autônomos, não estão subordinados hierarquicamente aos governos estadual ou central e não são obrigados a seguir determinações políticas ou administrativas. Por isso a submissão das unidades subnacionais ao governo central somente pode ser obtida a partir da manipulação de incentivos financeiros, possível apenas graças à posição privilegiada da união na estrutura fiscal.

Em auxílio à hipótese aqui apresentada, observe-se que de forma aparentemente contraditória, o mesmo governo central que se mostrou ao longo destes anos, tão favorável à participação do cidadão nos assuntos de administração local, não demonstra o mesmo nível de interesse quando se refere aos processos decisórios na esfera federal. É comum no Brasil avaliar-se que a Constituição de 1988 incorporou a participação direta do cidadão nos processos decisórios com a institucionalização do plebiscito, do referendo e da apresentação 
de leis por iniciativa popular. Mas a realidade é que duas décadas depois da promulgação daquela carta, se observa que tais instrumentos raramente foram ativados. Em vinte anos foram realizados apenas um plebiscito, pelo qual se consagrou o regime presidencialista de governo, e um referendo, que revogou uma lei que restringia o porte de armas de fogo pela população civil. É interessante notar que o plebiscito sobre o regime de governo estava previsto pela Constituição de 1988 em suas Disposições Transitórias, ou seja, não foi convocado por vontade dos governantes da época. Por fim, um eminente jurista observou recentemente que a atual Constituição federal já recebeu nada menos que 68 emendas, sem que a população jamais tenha sido chamada a opinar sobre tais alterações (COMPARATO, 2010). Estamos, portanto, diante de fortes indicativos de que a elite no poder durante as cinco legislaturas posteriores à promulgação da carta constitucional não demonstrou interesse em compartilhar com os cidadãos o poder concentrado na esfera federal.

Quanto à apresentação de projetos de lei por iniciativa popular, dificuldades não previstas na regulamentação original praticamente inviabilizaram o dispositivo constitucional. Não fosse a dificuldade de se obter por intermédio de abaixo-assinados a adesão de $1 \%$ do total de eleitores registrados, "distribuído pelo menos por cinco Estados, com não menos de três décimos por cento em cada um deles", permanece o problema de contabilizar e, principalmente, conferir assinaturas e respectivos números de documentos ${ }^{9}$ para validar a iniciativa. Com isso, até hoje nenhum projeto apresentado ao Congresso como sendo de "iniciativa popular" tramitou sem que houvesse sido assinado por um parlamentar que assumisse, pelo menos tecnicamente, a autoria dos mesmos. Esse artifício, entretanto, retira da sociedade civil a autonomia na proposição de projetos, tornando necessário que algum parlamentar encampe a medida, ou seja, na prática ele obriga o retorno ao sistema tradicional, onde representantes assumem como suas, demandas oriundas da sociedade civil e tentam convertê-las em leis ou políticas. A participação por intermédio de abaixoassinados e petições é legítima e deve ser estimulada, mas dentro do sistema representativo tradicional ela não requer regulação constitucional e a possibilidade constitucional de legislação por iniciativa popular não pode ser reduzida à apresentação de abaixo-assinados aos parlamentares.

Esse comportamento, aparentemente, contraditório de uma elite central que patrocina a disseminação de instrumentos de participação no nível local, ao mesmo tempo em que recusa a mesma participação nos assuntos federais encontra explicação nos quadros da hipótese aqui sugerida: a estratégia de submissão do poder local, iniciada com a subtração da autonomia fiscal e orçamentária dos municípios nos anos 1990, se completaria então com o "controle social" exercido pela sociedade civil sobre os governos locais. Ocorre que as administrações municipais no atual sistema federativo brasileiro apresentam reduzido $\overline{\text { 9- Ao lado de cada assinatura }}$ deve constar o número do título de eleitor, a identificação da zona e da seção eleitoral 
grau de interferência no desenho das políticas socais, que são definidas em nível federal (Cf. Arretche e Vazquez, 2009). Embora áreas fundamentais da administração pública estejam constitucionalmente sob a competência das administrações locais é flagrante a incapacidade dos municípios de arcarem com os custos de manutenção dos serviços de saúde, educação e assistência social ou com volumosos investimentos em infraestrutura urbana e saneamento básico, tornando-os reféns dos repasses de recursos ou de investimentos diretos do governo central. Cálculos apresentados por Celina Souza (2004) mostram que a receita própria de $74,8 \%$ dos municípios brasileiros representa apenas $7 \%$ do total dos seus recursos. Os municípios são, portanto, no seu conjunto, incapazes promover políticas adequadas aos interesses da sociedade local independentes da mediação das elites centrais. Dessa perspectiva, os conselhos e as conferências municipais não são instituições de descentralização política ou administrativa. São, sobretudo, instrumentos através dos quais o poder central tenta submeter os governos subnacionais utilizando em seu favor o "controle social", ou seja, utilizando a participação da população como instrumento para submeter o poder local e garantir que a política desenhada no nível do governo central seja rigorosamente aplicada pelos governos locais, apesar da autonomia conferida pela Constituição aos municípios alçado à condição de entes federados.

O papel que é reservado à participação popular na estratégia das elites, entretanto, não é de fácil execução, pois os governantes nos municípios, ainda que frágeis diante do governo central, são poderosos em nível local e conseguem exercer forte influência sobre a dinâmica de funcionamento das instituições participativas. Eles dominam os cargos diretivos dos conselhos, controlam suas agendas e orientam a ação de representantes da sociedade civil, manipulando informações técnicas e jurídicas, quando não seduzem parte destes representantes mediante a oferta vantagens ou compensações políticas. Afinal, o domínio oligárquico e seus filhotes comuns como o clientelismo, o mandonismo, o coronelismo etc. não são fictícios; são fenômenos históricos reais e possuem sólidas bases sociológicas que permanecem vigentes pelo menos em dois aspectos. $\mathrm{O}$ primeiro, diz respeito à extrema desigualdade econômica que caracteriza a sociedade brasileira e que projeta uma pequena, porém poderosa, elite ao lado de uma numerosa massa que por não dispor de outros recursos se coloca a serviço daquela elite como forma de garantir sua sobrevivência. O outro, ainda que elucidado por Vitor Nunes Leal há mais de meio século, permanece, em larga medida, ignorado. O "coronelismo", como fenômeno típico da política brasileira que se manifesta na forma de uma submissão completa dos aparelhos de governo aos desígnios do mandatário no poder não encontra explicação apenas no poderio das oligarquias locais, mas também na fragilidade das instituições republicanas, entre elas a fraqueza dos municípios no interior do arranjo federativo erguido com a república. Poucos se lembram que o clássico "Coronelismo, Enxada e Voto", tem como subtítulo "o município e o regime representativo no Brasil" e que nele já estava escrito com todas as letras: 
“(...) a falta de autonomia legal do município nunca chegou a ser sentida como problema crucial, porque sempre foi compensada com uma extrema autonomia extralegal, concedida pelo governo do Estado ao partido local de sua preferência. (....) Com tais medidas, só os adversários ficavam realmente prejudicados: de uma parte, a corrente local governista sempre obteria do Estado o que reputasse indispensável e, de outra, quanto maior a dependência da comuna, tanto maiores as probabilidades de vitória da facção situacionista nas próprias eleições municipais". (LEAL, 1975; p. 255.)

Em síntese, a subtração da autonomia dos municípios não apresenta como resultado somente o enfraquecimento das elites locais. Ao contrário, estas se aproveitam da fragilidade manifestada dos governos locais, incapazes de atender minimamente as demandas da população sem o concurso do poder central, para colocar em movimento uma poderosa máquina clientelista sempre pronta a barganhar apoios com as forças que ocupam o governo em nível estadual e/ou federal recebendo em troca benesses que, por sua vez, competem para fortalecer a sua condição perante a fração oposicionista da elite (quase sempre há uma parte da elite na oposição) e, principalmente, para fortalecer sua condição de dominante perante as classes subalternas.

A contradição presente nesse esquema é que ao fazer uso da participação popular para seus fins de controle sobre as elites locais, o governo central não pode impedir que os setores subalternos, eventualmente, usem essa estrutura participativa para realizar projetos populares, mesmo que para isso ela tenha que travar uma disputa encarniçada com as elites locais em uma estreita margem de deliberação deixada pelo governo central. Mas essa não é a regra. É fenômeno esporádico que ocorre apenas em conjunturas especiais de intensa mobilização de movimentos sociais e/ou da fração oposicionista da elite local. A regra, pelo que temos visto, é que "o povo não participa". Ocorre que a estratégia das elites centrais conta com a participação da sociedade civil entendida como uma espécie de imperativo moral, pelo qual o cidadão deve participar porque é correto que ele participe, ou então, em uma versão mais republicana, porque sua participação é necessária para a realização de uma pretensa "vontade geral" interpretada pela elite central, mas não para fazer valer algum interesse próprio, ou realizar um projeto distinto daquele definido nas instâncias superiores (mesmo que eventualmente isso possa acontecer). Por isso, quando a participação esperada não acontece, o julgamento é sumário e aponta sempre para uma suposta fragilidade moral da população: o povo não participa, porque é "desinteressado", "desinformado", "acomodado" etc. Este julgamento moral, ao condenar o povo, inocenta as elites, oculta a debilidade das instituições participativas e, ipso facto, da democracia entre nós. 


\section{REFERÊNCIAS E BIBLIOGRAFIA}

ALMEIDA, M. H. T. de; CARNEIRO, L. C. (2003). "Liderança local, democracia e políticas públicas no Brasil”. Revista Opinião Pública, Vol. IX, n1,.Campinas.

ARRETCHE, M. e VAZQUEZ, D. (2009). "Descentralização, instituições políticas e autonomia: padrões de gasto dos governos locais no Brasil". Prepared for delivery at the 2009 Congress of the Latin American Studies Association, Rio de Janeiro, Brazil June 1114, 2009. Disponível em: http://www.cultiva.org.br/pdf/arretche_marta_gastos_municipais. pdf (Ultimo acesso em 15/03/2010).

BIELSCHOWSKY, R. (1995). O Pensamento Econômico Brasileiro: o ciclo ideológico do desenvolvimento. Contraponto, Rio de Janeiro.

BRANDÃO, Carlos R. (1990). O Trabalho de Saber: cultura camponesa e escola rural. Editora FDT, São Paulo.

COMPARATO, F. K. (2010). "Nem República, nem Democracia". Revista Carta Capital, São Paulo, n. ${ }^{\circ}$ 578, p. 54-9, 13 jan. 2010. Entrevista concedida a Gilberto Nascimento e Walter F. Maierovitch.

DOMBROWSKI, O. (2008). "Poder Local, Hegemonia e Disputa: os conselhos municipais em pequenos municípios do interior". Revista de Sociologia e Política, v. 16, $\mathrm{n}^{\circ}$ 30, UFPR, Curitiba.

DOMBROWSKI, O. ; PARMIGIANI, J. (2009). "Não Quero Saber dos seus Conselhos: considerações sobre a nossa democracia participativa". Comunicação apresentada ao $4^{\circ}$ Seminário Nacional Estado e Políticas Sociais. Cascavel: EDUNIOESTE,

DOWNS, A. Uma teoria econômica da democracia. São Paulo: Edusp, 1999.

LEAL, Vitor N. (1975). Coronelismo, enxada e voto: o município e o regime representativo no Brasil. Alfa-Omega, São Paulo.

OLSON, M. (1999). A lógica da ação coletiva. Edusp, São Paulo.

PÉCAUT, D. (1990). Os intelectuais e a política no Brasil: entre o povo e a nação. Ática, São Paulo.

SANTOS JR., O. A.; AZEVEDO, S. \& RIBEIRO, L. C. Q. (Orgs.) (2004). Governança democrática e poder local: a experiência dos conselhos municipais no Brasil. Revan, Rio de Janeiro.

SILVA, M. S. (2002). "Federalismo fiscal no Brasil: arrecadação, transferências e disponibilidades (1988 - 2000)”. Dissertação apresentada ao Curso Mestrado em Administração Pública, Fundação Getúlio Vargas, Rio de Janeiro.

SOUZA, C. (2004). "Governos locais e gestão de políticas sociais universais". Revista São Paulo em Perspectiva, Vol. 18, n. 2, Fundação SEAD, São Paulo.

VARSANO, R. (1998). "Evolução do Sistema Tributário Brasileiro ao Longo do Século". Texto para Discussão $n^{\circ} 405$, IPEA, Rio de Janeiro.

VIANNA, O. (2005). Populações meridionais do Brasil. Conselho Editorial do Senado Federal, Brasília. 